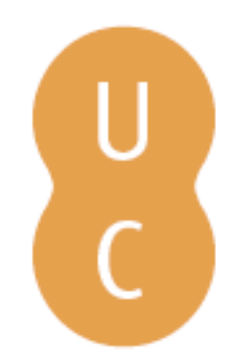

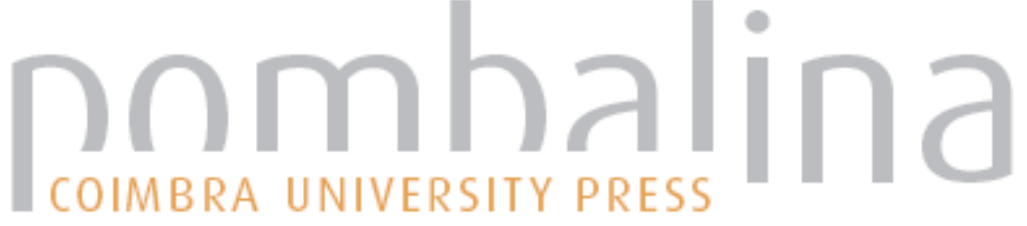

\section{As novas promessas do multilateralismo}

Autor(es): $\quad$ Fernandes, Sandra; Simão, Lucínia

Publicado por: Imprensa da Universidade de Coimbra

URL persistente:

URI:http://hdl.handle.net/10316.2/47537

DOI:

DOl:https://doi.org/10.14195/978-989-26-1750-3_11

Accessed : $\quad$ 26-Apr-2023 13:48:28

A navegação consulta e descarregamento dos títulos inseridos nas Bibliotecas Digitais UC Digitalis, UC Pombalina e UC Impactum, pressupõem a aceitação plena e sem reservas dos Termos e Condições de Uso destas Bibliotecas Digitais, disponíveis em https://digitalis.uc.pt/pt-pt/termos.

Conforme exposto nos referidos Termos e Condições de Uso, o descarregamento de títulos de acesso restrito requer uma licença válida de autorização devendo o utilizador aceder ao(s) documento(s) a partir de um endereço de IP da instituição detentora da supramencionada licença.

Ao utilizador é apenas permitido o descarregamento para uso pessoal, pelo que o emprego do(s) título(s) descarregado(s) para outro fim, designadamente comercial, carece de autorização do respetivo autor ou editor da obra.

Na medida em que todas as obras da UC Digitalis se encontram protegidas pelo Código do Direito de Autor e Direitos Conexos e demais legislação aplicável, toda a cópia, parcial ou total, deste documento, nos casos em que é legalmente admitida, deverá conter ou fazer-se acompanhar por este aviso. 
SANDRA FERNANDES LICÍNIA SIMÃO

(COORDS.)
IMPRENSA DA

UNIVERSIDADE

DE COIMBRA

COIMBRA

UNIVERSITY

PRESS

\section{O MULTILATERALISMO}

CONCEITOS E PRÁTICAS NO SÉCULO XXI

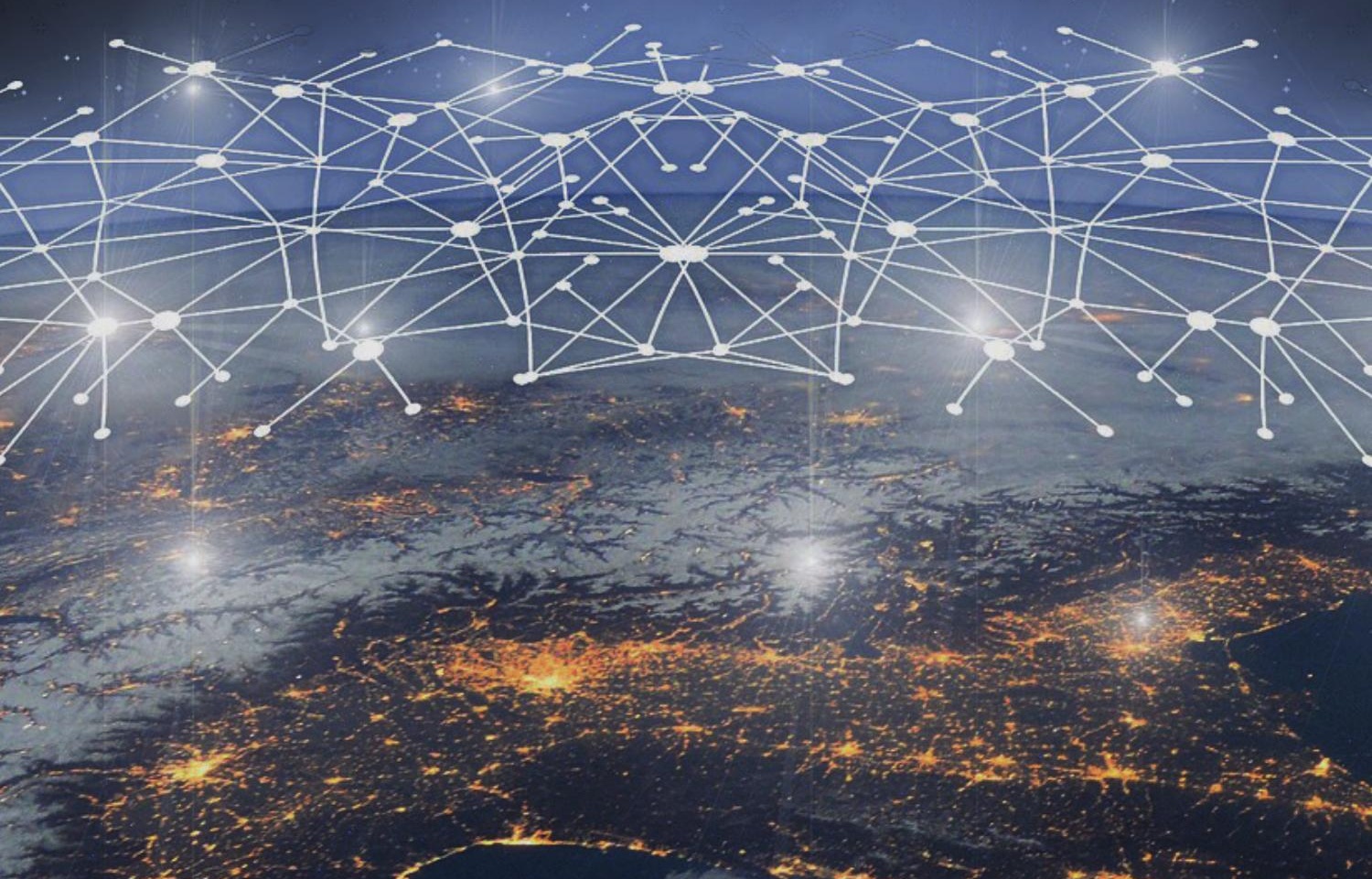




\section{AS NOVAS PROMESSAS DO MULTILATERALISMO}

SANDRA FERNANDES

Universidade do Minho e Centro de Investigação em Ciência Política (CICP), Portugal. ResearcherID: O-1155-2013

ORCID: http://orcid.org/0000-0002-3994-6915

\section{LICÍNIA SIMÃO}

Faculdade de Economia e Centro de Estudos Sociais da Universidade de Coimbra, Portugal. ORCID: https://orcid.org/0000-0001-5479-8925

A análise coletiva conduzida nesta obra revela a centralidade atual das práticas multilaterais nas relações internacionais, tanto à escala regional como global. Pese embora as dinâmicas internacionais exibirem, no início do século XXI, padrões muito fluídos, de menor previsibilidade, com elementos como a personalidade dos líderes políticos ou os media a impactarem de forma surpreendente as estruturas de gestão global, a permanência da prática multilateral apresenta-se como um fenómeno de continuidade e estabilidade. Seja na sua forma institucionalizada, através da criação de organizações regionais (veja-se o exemplo das iniciativas lideradas pela Federação Russa no espaço euroasiático ou da China na Ásia) ou tratados internacionais (como é o caso do acordo para combater as alterações climáticas, assinado em Paris, em 2016, ou os Objetivos de Desenvolvimento Sustentável), seja através de normas e princípios internacionais que são partilhados globalmente, o multilateralismo permanece um elemento estabilizador da ordem internacional.

Pela sua ação constrangedora do comportamento dos atores participantes nos arranjos multilaterais, esta opção de política externa mantém uma relação profundamente ambígua com outras abordagens praticadas pelas grandes potências. Confirma-se, assim, a ideia segundo a qual os Estados poderosos não gostam do multilateralismo, preferindo interações bilaterais ou unilaterais, mas que não o conseguem evitar para alcançar os resultados desejados. Olhando para os Estados Unidos da América (EUA), os mentores da ordem 
liberal que ainda hoje define as principais regras do jogo interestatal, fica clara a crescente tensão entre a necessidade de um mundo regulado em torno de agendas de interesse comum e a tentação de usar vastos recursos de poder de forma unilateral. A inserção multilateral de Washington cria-lhe desconforto quando evolui num espaço mais complexo e interdependente, onde as vontades de outros Estados e povos também procuram pesar. A sua relação com as questões da paz e da segurança internacionais ilustram particularmente bem como os EUA têm procurado beneficiar da institucionalização de um modelo de paz liberal. Se por um lado este modelo, legitimado nos princípios da democracia liberal e dos direitos humanos, tem permitido uma série de intervenções internacionais, só possíveis pela natureza multilateral dos quadros institucionais que as legitimam (nomeadamente a ONU e o seu Conselho de Segurança), por outro lado tem criado também obrigações normativas à potência hegemónica do fim da Guerra Fria e um contexto global de enorme contestação à ordem liberal que ela lidera (incluindo na sua dimensão económica).

A emergência da China como uma potência regional asiática, mas também, crescentemente, como uma potência global, evidencia padrões onde o multilateralismo tem um papel central. A China promove práticas multilaterais à escala regional de modo a modificar a ordem liberal económica e financeira gerida por organizações tais como o Fundo Monetário Internacional e o Banco Mundial, liderados pelas potências ocidentais. As iniciativas com vista à consolidação da sua presença económica e financeira na Ásia demonstram, por um lado, um entendimento de poder ligado claramente ao domínio de recursos económicos, financeiros e naturais, e, por outro lado uma necessidade de alavancar a estratégia de projeção global na consolidação da sua presença regional. Em ambos os casos, o multilateralismo tem criado oportunidades importantes para a República Popular da China contestar a liderança ocidental e, em particular, dos EUA. Para além de instrumento ao serviço do Estado hegemónico regional, o multilateralismo permite substituir uma ordem contestada. As suas atividades no âmbito dos BRICS, nomeadamente a criação do Novo Banco de Desenvolvimento, ilustram particularmente bem estas dinâmicas. Pelo contrário, países emergentes ou mesmo pequenos/médios, como o Brasil e Portugal, fazem do multilateralismo um verdadeiro instrumento de 
política externa onde a inclusão e a participação nos formatos multilaterais são sinónimos de influência. No caso português, a opção multilateral ascendeu a prioridade política no sentido de concretizar o seu triplo posicionamento enquanto país europeu, atlântico e lusófono. O multilateralismo tem sido entendido como uma oportunidade de participação e de acesso a recursos fundamentais para a prossecução dos interesses estratégicos de Portugal, no contexto pós-autoritário e colonial. Aliás, nesse processo, a participação multilateral tem sido frequentemente equacionada com a democratização do país e com o seu compromisso fiel com os princípios liberais ocidentais. O caso do Brasil permite-nos entender duas dimensões importantes das dinâmicas multilaterais. A primeira é a sua permanência como um elemento definidor dos entendimentos de poder estatal no século XXI. A participação em formatos multilaterais continua a ser vista como um elemento prestigiante e que confere poder negocial aos Estados, através da criação de alianças e da alavancagem de recursos partilhados. A política externa brasileira tem evidenciado estas dinâmicas de forma clara, particularmente nos mandatos de Lula da Silva. A segunda dimensão, contudo, releva alguma ambiguidade na forma como as potências emergentes investem no desenvolvimento das estruturas multilaterais, já que por um lado exibem padrões de instrumentalização do multilateralismo semelhantes a outros Estados (a procura de parcerias com outras potências, por vezes minando os objetivos da ordem multilateral vigente, demonstram isso) e, por outro lado mantêm oscilações importantes na sua política externa, que ditam, em algumas circunstâncias, um desinvestimento da lógica multilateral, como foi o caso dos mandatos da Presidente Dilma Rousseff.

Estas leituras do fenómeno multilateral, a partir da base estatal, colocam em evidência uma outra dinâmica que, não sendo específica do multilateralismo, o afeta no âmbito do exercício da política externa dos Estados que o sustentam. A relação entre política externa e política interna é fundamental para entendermos as variações no compromisso com as lógicas multilaterais. Seja pela real pressão doméstica para que se abandone ou se reforce a participação multilateral, seja pelo uso instrumental dessa potencial pressão para evitar ou reforçar compromissos, o multilateralismo, enquanto opção da política externa dos Estados, permanece refém das lógicas de gestão de inte- 
resses. Contudo, um entendimento estritamente estatal do multilateralismo não permite entender as mudanças profundas que o século XXI abraçou, no que toca à capacidade de diferentes tipos de atores moldarem a política internacional e, por inerência, também o multilateralismo. A participação de atores da sociedade civil, incluindo Organizações Não-Governamentais (ONG) e empresas comerciais, como parceiros de organizações regionais e globais como a ONU, permite entender os novos desafios que se colocam. Isto permite aos cidadãos tentar moldar diretamente as dinâmicas globais, através das plataformas multilaterais, para lá da sua representação pelos seus Estados nacionais. Isto subentende a formação de coligações transnacionais de interesse que veem nas organizações formais uma possibilidade de ação, mas subentende também um entendimento do exercício de poder que é ideacional e material, criando oportunidade para readaptar, reenquadrar e redesenhar as dinâmicas internacionais,

A análise das Nações Unidas e da União Europeia mostra estas oportunidades de participação, embora o peso das vontades nacionais ainda determine, em larga medida, o sucesso das agendas promovidas por estes atores. O papel destas instituições deve ser, por isso, entendido nessa tensão permanente entre as instituições criadas e as vontades dos Estados que as criaram. As abordagens institucionalistas ajudam-nos a entender como as instituições ganham vida própria, para lá das intenções iniciais dos Estados e como estes procuram limitar esta dinâmica, à medida que os seus interesses evoluem. O papel da ONU na definição da agenda global de paz e segurança é um caso interessante para demonstrar estas tensões, já que a pressão dos Estados membros sobre a instituição se faz sentir de diversas formas: na definição do quadro normativo de atuação e a sua legitimação, na disponibilização de recursos financeiros e materiais para a persecução do seu mandato, na priorização política de alguns contextos geográficos e temáticos sobre outros. Por outro lado, o espaço amplo de participação que a ONU representa, incluindo para atores não-estatais, tem permitido que diferentes agendas se contaminem, criando sinergias que levam a que aspetos marginais ganhem prominência, como é o caso da ligação das agendas de segurança, direitos humanos e direitos da infância. Embora estas ligações apresentem problemas específicos, elas mostram como as plataformas multilaterais criam oportuni- 
dades de participação que escapam ao controlo total dos Estados e das suas vontades nacionais.

A União Europeia, pela natureza multinível da sua governação, apresenta-se como um ator particularmente interessante para o estudo do fenómeno multilateral. As dinâmicas internas de gestão dos interesses dos Estados Membros e das instituições europeias configura um espaço de negociação multilateral de direito próprio, que a UE procura externalizar nas suas relações com países terceiros. Por outro lado, a defesa do princípio do multilateralismo efetivo, tornada explícita na Estratégia Europeia de Segurança de 2003 e promovida através de uma colaboração estreita com organizações internacionais como a ONU e outras de âmbito regional, em todos os continentes, torna a UE um dos atores internacionais mais comprometidos com uma certa visão do multilateralismo, assente em organizações e tratados internacionais. A UE, pela sua relação umbilical com os EUA, tem também sido uma promotora da paz liberal e do intervencionismo em seu nome. Contudo, há pressões fortes sobre este compromisso, alavancadas pelo atual contexto internacional de maior pendor nacionalista e menos cosmopolita e internacionalista. A própria falta de coerência das políticas europeias, nomeadamente na gestão dos acordos comerciais com outras potências, prosseguida ao longo da última década fora do quadro da OMC e privilegiando rondas negociais bilaterais, contribui para minar o princípio multilateral. Adicionalmente, a falta de visão comum dos Estados Membros, em temáticas fraturantes como são as relações com a Federação Russa ou a gestão das crises internacionais, aprofundam essa dinâmica, ao mesmo tempo que a falta de capacidades militares da UE tem contribuído para a tornar um parceiro menos previsível. Assim, a Estratégia Global da UE, de 2016, apresenta um compromisso menos sólido com o multilateralismo e reconhece a necessidade de a UE poder avaliar cada situação casuisticamente, com base nos princípios da diferenciação e da resiliência das sociedades vizinhas.

O livro aponta para a natureza multinível do multilateralismo, em que coexistem formatos regionais, influências nacionais e enquadramentos mais globais. A constelação de práticas analisadas advém, portanto, da existência simultânea de dinâmicas, cuja materialização determina os alcances e as limitações do multilateralismo. Destacamos quatro dinâmicas atuais: a variedade 
dos formatos de cooperação, a instrumentalização dos mesmos em concomitância com a sua inelutabilidade, o cruzamento das agendas e a multiplicidade dos atores envolvidos.

A grelha de análise realista - que vê no multilateralismo uma ferramenta para os mais poderosos projetarem os seus interesses e que vê perigos de segurança e estabilidade internacional nas limitações que o multilateralismo impõe à política externa dos Estados - deixou claramente de ser suficiente para explicar um mundo cuja mutação rumo à interdependência surge logo a partir dos anos 1970. Esta alteração nas dinâmicas internacionais impulsionou um conjunto de reflexões teóricas sobre as relações internacionais que se fizeram também refletir no seu entendimento sobre o multilateralismo. Assim, a globalização dos sistemas económicos e comerciais, alavancada pelo próprio multilateralismo pós-Guerra, criou os mecanismos que permitiam imaginar a gestão dos bens públicos globais a partir de lógicas de compromisso e ganhos mútuos. As abordagens liberais institucionalistas procuraram assim evidenciar o papel das normas e das instituições em providenciar ganhos de eficiência e de estabilidade da ordem internacional, incluindo para as suas principais potências.

A interdependência securitária da Guerra Fria reforçou esta lógica, mas subverteu-a a partir da ótica do multilateralismo subserviente aos interesses e liderança das duas superpotências. Será a interdependência ambiental da década de 80 e a abertura política do pós-Guerra Fria, que irão contribuir para a criação de uma perceção comum da humanidade e para uma agenda de mobilização cosmopolita, que irá culminar na ligação entre as agendas de direitos humanos e segurança e no reforço do ativismo de base normativa que o multilateralismo onusiano irá refletir de forma particularmente visível. Mais uma vez, refletindo essa relação dialógica, as abordagens teóricas das Relações Internacionais irão procurar incorporar o papel das ideias e da interação social na constituição da agenda e das práticas internacionais. O construtivismo surge, assim, como um fator de análise fundamental para explicar, para lá dos constrangimentos institucionais, como as normas comuns são um fator na gestão das causas globais e no multilateralismo.

Entre as abordagens críticas, quer as explicações sistémicas, como o Marxismo, quer as explicações de base discursiva, invocam um universo mais 
amplo, onde a participação na lógica multilateral se faz a partir de imaginários de possibilidades legítimos assentes em estruturas de poder desiguais. A legitimação de certos modelos de atuação e de governação das questões globais é vista, a partir destas lentes, como refletindo formas de pensar hegemónicas e por isso constitutivas de relacionamentos hierárquicos. Nesta perspetiva, a emancipação humana e a transformação positiva das causas dos conflitos dependem de um rompimento com as normas estabelecidas. O multilateralismo serve, essencialmente, aqueles que o dominam.

O multilateralismo é hoje um sistema variado e complexo. Se ainda é materializado por instituições formais e instrumentalizado pelos Estados com objetivos de afirmação, ele pena em evoluir em direção a um mundo onde as necessidades de governação global se adensam face ao número crescente dos bens globais. Para além de um diagnóstico sobre o fenómeno multilateral enquanto elemento definidor das relações internacionais do século XXI, finalizamos com um debate essencial sobre a ideia de "integração internacional". Sendo os conflitos atuais longos e de cada vez mais de difícil resolução, já que escapam às lógicas estatais, olhar o mundo através dos indivíduos e das sociedades que o compõem surge como um desafio adequado. No longo prazo, a paz mundial só poderá emergir de uma atenção às "patologias sociais da mundialização", portadoras de violência e ressentimento. ${ }^{1}$ Num planeta onde as agendas políticas centrais assumem uma dimensão global, o multilateralismo, em particular nas suas formas institucionalizadas, precisa de se reformar de modo a servir para a construção de contratos sociais onde todos, no centro e na periferia do sistema, possam participar. A prazo, as práticas multilaterais poderiam propiciar a emergência de uma cidadania global.

${ }^{1}$ A ideia de integração, relações intersociais e de patologias da mundialização são teorizadas no âmbito da perspetiva sociológica das relações internacionais de Bertrand Badie. 